\title{
How much would it cost to reduce class size by one student?
}

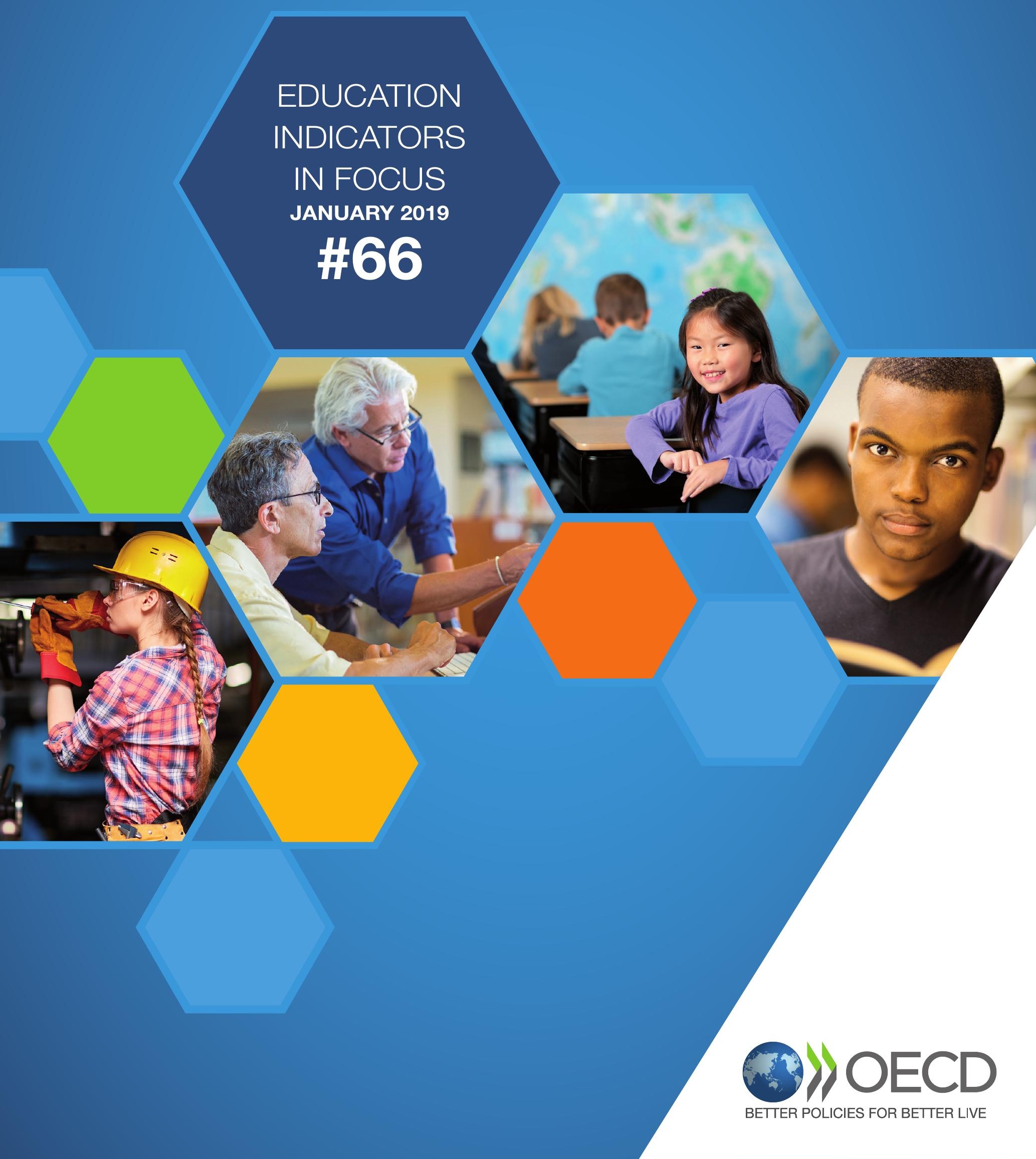


- Class sizes have been falling in many OECD countries. Between 2005 and 2016. the average class size in lower secondary public institutions fell in 18 of the 24 OECD countries with available data. These decreases are often the result of changing demographics, although cutting class sizes can also be a popular policy move with teachers and parents.

- Evidence on the effects of smaller class sizes is mixed, suggesting that they may only be beneficial for some students and under certain circumstances - and they come at a cost. In lower secondary education, funding the additional teachers needed to reduce the average class size by one student would increase the cost per student by around USD 300 per year on average across OECD countries, unless offsetting adjustments are made.

- If countries want to reduce average class size and keep spending constant, they can finance this change through lower teachers' salaries, longer teaching hours or shorter instruction time. Across OECD countries spending similar amounts per student, those with smaller class sizes tend to have lower teacher salaries. Given the high cost of reducing the average class size by one student, it is important to assess whether and in what circumstances the trade-offs are worth it.

\section{How is the salary cost of teachers calculated?}

Teachers' salary cost is a measure of a country's overall spending on teachers' salaries. In addition to teachers' salaries themselves, the indicator takes into account three factors that influence the number of teachers required in a system: the number of required instruction hours, the number of hours teachers spend teaching and the estimated class size. Box 1 defines each of these factors, and Figure 1 illustrates how they relate to each other and combine to produce the salary cost of teachers.

FIGURE 1 / Illustration of how the salary cost of teachers for a given educational level is computed using teachers' salary, instruction time, teaching time and estimated class size.

School with 100 students:



So each class needs 2 teachers, and the school needs 10 teachers.

Salary Cost = Salary * $\left[\frac{\text { Instruction time }}{\text { Teaching time }} * \frac{\text { Students }}{\text { Class size }}\right] \vdots{ }^{\prime}$ Estimated number of teachers 
Given the mathematical relationship between the four factors, it is possible to use the model as a simulator and assess the direction and size of the trade-offs needed to compensate for changes in one factor. For example, assuming that the number of students and the salary cost remain constant, what potential trade-offs could be made among the other factors that would compensate for a smaller class size? More specifically, by how much would salaries or instruction time have to decrease, or teaching time have to increase, in order to maintain the same salary cost?

This theoretical simulation is not meant to assess the real cost of reforms. The indicator uses the statutory value of each factor, which may differ considerably from the actual values in each country. Moreover, this simple model only takes into account four factors, and it only shows the trade-off of one factor at a time. In reality, trade-offs will often consist of changes in several factors at the same time. In addition, significant regional variations, which this indicator does not capture, may require specific policies that would not necessarily be reflected in the national averages. Instead, this analysis is only meant to highlight the importance of trade-offs in policy decisions, particularly across the four factors assessed in this indicator.

\section{Box 1. Definitions}

- Estimated class size is the average size of classes taking into account instruction and teaching time. It is calculated as: Estimated class size $=\frac{\text { Instruction time }}{\text { Teaching time }} * \frac{\text { Students }}{\text { Teaching }}$

- Instruction time refers to the time a public school is expected to provide instruction to students on all the subjects integrated into the compulsory and non-compulsory curriculum, on school premises or in before- or after-school activities that are a formal part of the compulsory programme.

- Salary cost per student is calculated as: Salary cost of teachers per student = Teacher salary* Instruction time * $\frac{1}{\text { Teaching time }} * \frac{1}{\text { Estimated class size }}$

- Teachers' teaching time is the annual statutory number of hours that full-time teachers teach a group or class of students including all extra hours, such as overtime.

- Teachers' salary refers to the annual statutory salary (according to official pay scales) of teachers with the most prevalent qualifications after 15 years of experience, converted to USD using purchasing power parity (PPP) for private consumption.

\section{Potential trade-offs between class size, teacher salaries, instruction time and teaching time}

On average across OECD countries, the annual salary cost of teachers per student in public institutions is USD 2900 in primary education and USD 3600 in lower secondary education. If countries were to reduce class sizes by one student, everything else being equal, this would require more teachers and would increase the salary cost of teachers per student by an average of around USD 250 in primary and USD 300 in lower secondary. However, it is possible to keep the total salary cost constant and offset the cost of smaller classes by making changes to the other factors instead.

So by how much would teachers' salaries have to be cut in order to compensate for a smaller class size? In 2016, the OECD average statutory salary for teachers with 15 years of experience was USD 44400 at lower secondary level. Figure 2 shows the annual cut in teachers' statutory salary in lower secondary education that would allow each country to reduce their estimated average class size by one student without increasing expenditure. The size of the reduction varies depending on the current levels of teachers' salaries and estimated class size in each country (see Box 1 for definitions). In Turkey, for example, where class sizes are large and teacher salaries are relatively low, a decrease in class size by one student could be offset by cutting teacher salaries by USD 800 a year. In Switzerland, the cut would have to be USD 5300 .

Alternatively, countries could keep both total spending and teachers' salaries constant and instead adjust the amount of time teachers spend in the classroom. This can be done in two ways: either by increasing the number of hours teachers spend teaching, or by reducing the number of hours for which students must be instructed. In both cases, this would decrease the number of teachers needed at a given educational level and thereby keep the overall wage bill constant.

Figure 3 shows by how much each country would need to either increase the teaching time or shorten the instruction time in order to compensate for a decrease in class size by one student. For example, Chile could entirely "pay" for this reduction by increasing annual teaching time by 78 hours. Alternatively, it could reduce students' required instruction time by 67 hours per year. For the purposes of this model and this cost analysis, what counts is the ratio between the two variables, meaning how much of the required instruction time is covered by one teacher's teaching time.

It is important to assess these potential trade-offs by taking into account the current situation in each country. For example, Chile already has the longest teaching time of all OECD countries, so further increases to compensate for smaller class size may be neither feasible nor desirable. 
FIGURE 2 / By how much would annual teachers' salaries have to decrease to compensate for decreasing class size by one student? (2016)

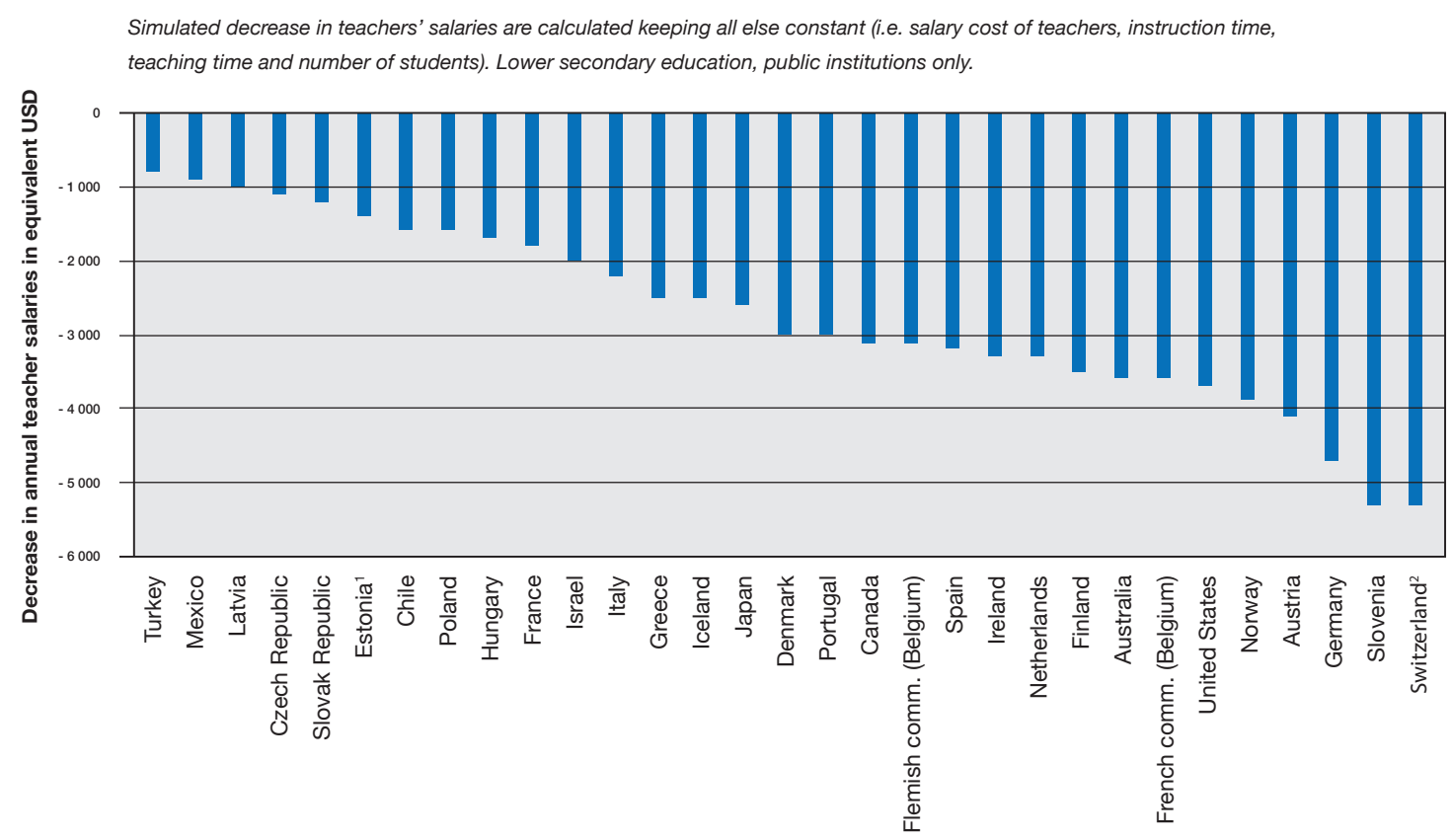

Note: Luxembourg has been removed from the chart because it is an outlier for teachers' salaries.

1. Teachers' statutory salaries at the start of their career instead of after 15 years of experience.

2. Teachers' statutory salaries after 10 years of experience instead of 15 years.

Source: OECD (2018 [1] $_{1}$, Education at a Glance 2018: OECD Indicators (https://dx.doi.org/10.1787/eag-2018-en.)

FIGURE 3 / By how much would instruction and teaching time have to vary to compensate for decreasing class size by one student? (2016)

Simulated increase/decrease in instruction time and teaching time are calculated keeping everything else constant. Lower secondary education, public institutions only.

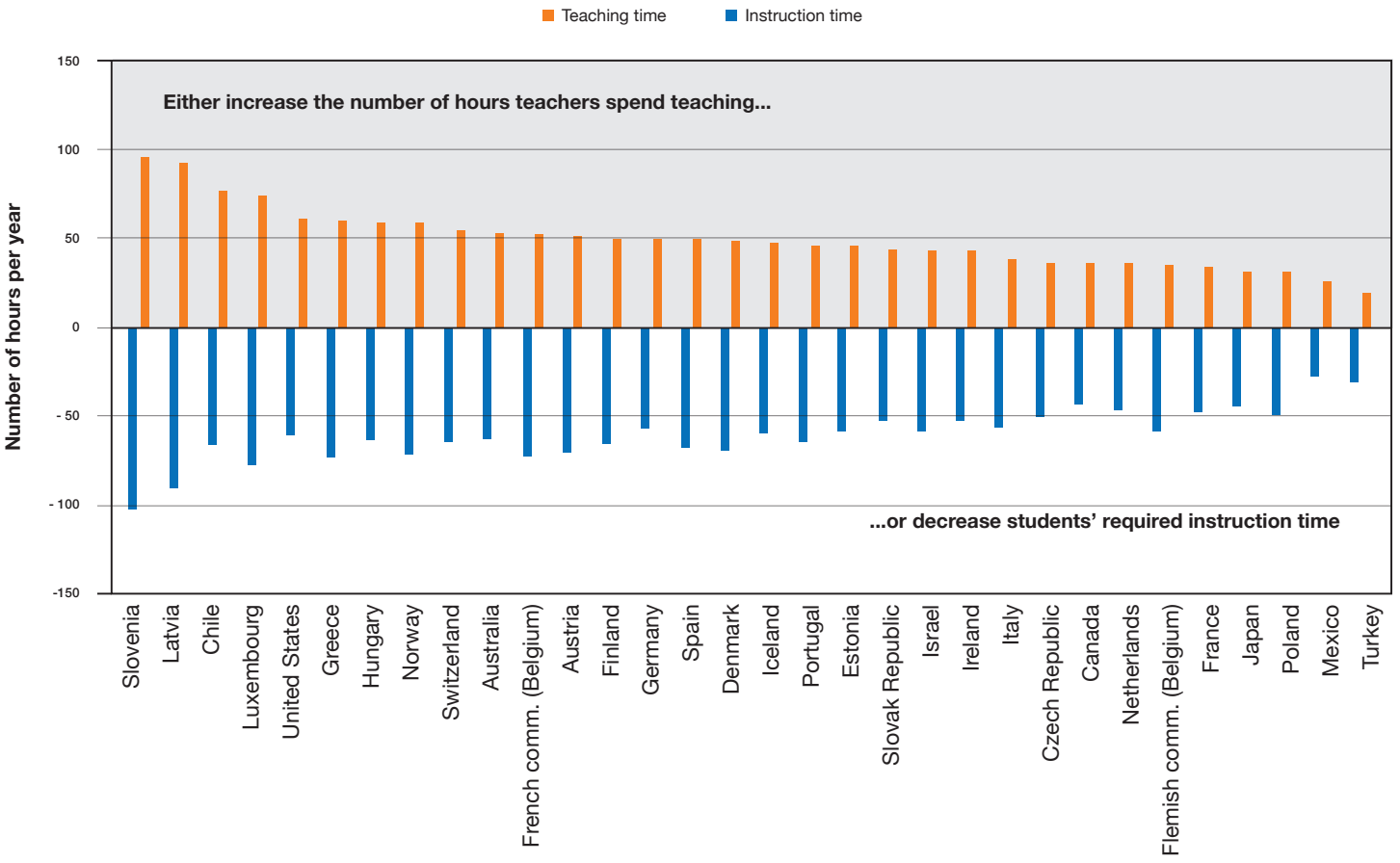

Source: OECD (2018 $\left.{ }_{[1]}\right)$, Education at a Glance 2018: OECD Indicators (https://dx.doi.org/10.1787/eag-2018-en). 


\section{Which trade-offs are countries choosing?}

Governments seek to provide more and better education for their population while ensuring that public funding is used efficiently, particularly when public budgets are tight. Most decisions, therefore, entail significant trade-offs. The analysis of the potential trade-offs across the four factors used to calculate the salary cost of teachers per student highlights the need to consider and carefully weigh the trade-offs associated with every change.

At each level of education, teachers' salaries generally have the largest impact on the level of countries' salary cost of teachers per student. The second most influential factor is the estimated class size. The trade-off between these two variables, which may be the aim of educational reforms and policies, reflects the choice some countries have to make between increasing teachers' salaries and hiring more teachers.

Figure 4 plots teachers' salaries against estimated class size, disaggregating between countries with above-average and below-average teachers' salary cost per student. It is important to control for the overall level of spending because, compared to low-spending countries, high-spending countries are able to afford more of everything (i.e. higher salaries and lower class sizes), which may give the misleading impression that they do not face trade-offs within their own budget allocation. The figure shows that, within each group of countries, the relationship between estimated class size and teachers' salary is positive, meaning that countries with higher teachers' salaries tend to have larger class sizes.

This result is confirmed through cross-country regressions. A simple regression of teachers' salary on estimated class size alone shows no significant relationship between the two variables. However, when controlling for salary cost, an increase in class size of one student in lower secondary education is associated with a USD 1300 increase in teacher salaries - and this result is significant at the $1 \%$ level.

Smaller class sizes are often seen as beneficial, but the evidence on their impact on student learning is mixed. Results from the latest Programme for International Student Assessment (PISA) show that students in larger classes score higher in science on average across OECD countries. Other research has found that smaller class sizes may be beneficial in some cases, such as for students from disadvantaged backgrounds and children in the early years of education who may need more individual attention (Dynarski, Hyman and Schanzenbach, 2013 $3_{[2]}$; OECD, 2018 ${ }_{[3]}$ ). Moreover, the effect of classsize reductions should not be expected to be linear, and may be more effective or only effective at all if the reduction is significant enough to enable teachers to engage in different pedagogical techniques.

FIGURE 4 / Relationship between teachers' salaries and estimated class size, disaggregated by level of salary cost of teachers per student (2016)

Lower secondary education, public institutions only.

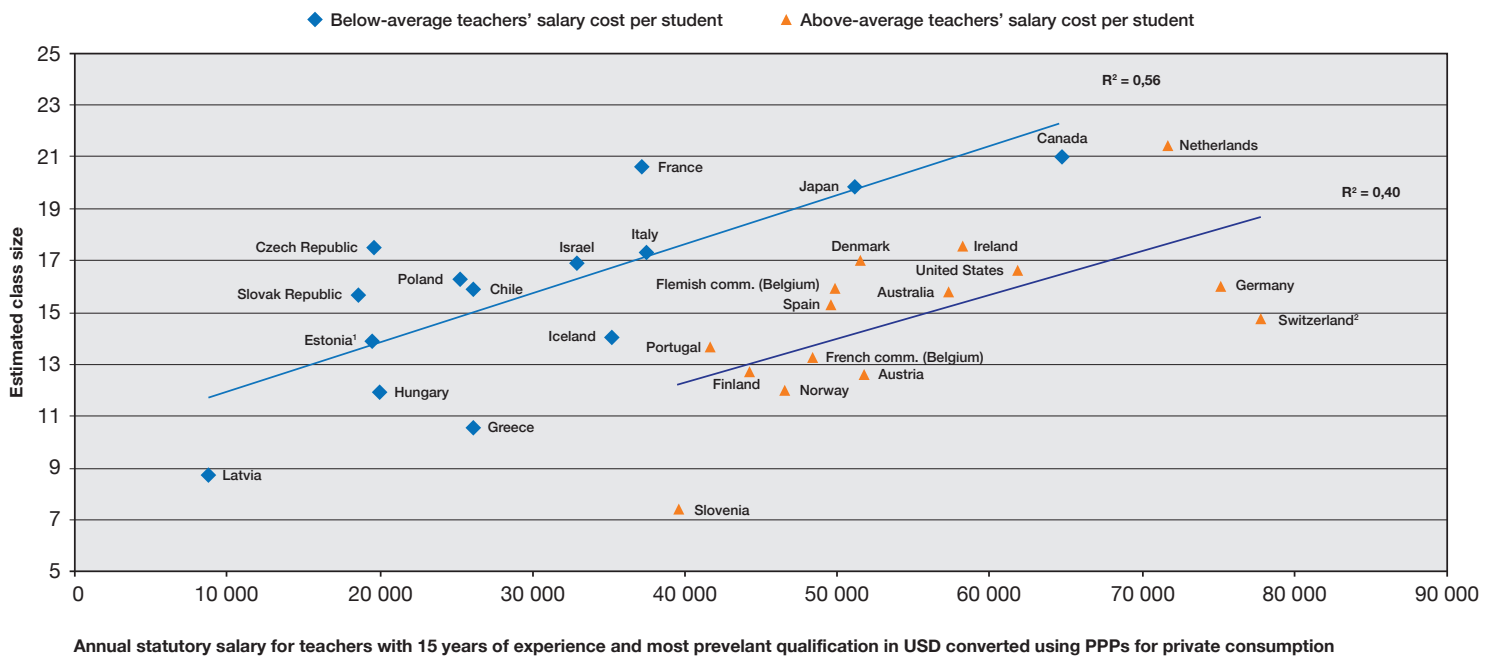

Note: Luxembourg, Mexico and Turkey have been removed from the chart and the average because they are outliers for either teacher salaries or estimated class size.

1. Teachers' statutory salaries at the start of their career instead of after 15 years of experience

2. Teachers' statutory salaries after 10 years of experience instead of 15 years.

Source: OECD (2018 $\left.{ }_{[1]}\right)$, Education at a Glance 2018: OECD Indicators (https://dx.doi.org/10.1787/eag-2018-en).

Across OECD countries, class sizes have been falling over the past decade. Between 2005 and 2016, the average class size in lower secondary public institutions has decreased in 18 of the 24 OECD countries with available data (OECD, 2018 $\left.{ }_{[11}\right)$. In many cases, the decrease was mostly due to demographic factors that reduced the number of students, without corresponding changes to the number of teachers and schools. 
Given that a smaller class size increases the cost per student, it is important to compare its impact with other possible interventions, such as increasing teachers' salaries $\left(O E C D, 2016_{[4]}\right)$. Evidence from an extensive body of research literature point to the importance of high-quality teaching in improving student outcomes, so it is important to find the most effective combination of policies for increasing the profession's attractiveness and teachers' motivation. Smaller class sizes and higher teacher salaries may be important factors shaping the profession, but there are several others as well. They include, for example, the quality of training before and after entering the profession, the status of the profession, and the relationship between teachers and society.

Trade-offs between the other factors are less clearly observed in cross-country analyses. Teachers' statutory salaries are weakly correlated with teachers' total working time (teaching and non-teaching time), but there seems to be no pattern across countries regarding teachers' salaries and teachers' teaching time. Moreover, although teaching and instruction time are highly correlated - the larger the number of statutory instruction hours, the longer the statutory teaching time there is no strong relationship between these factors and class size.

There is also little consensus among countries on the most effective policies related to instruction time. The organisation of the school day, as well as the methods used for teaching and learning, seem to be more important factors than the actual number of hours spent in school (Gromada and Shewbridge, 2016 ${ }_{[5]}$ ). The wide variation across low- and high-performing countries on instruction and teaching time suggests that these factors alone are not enough to guarantee better student outcomes (OECD, 2016 $\left.{ }_{[6]}\right)$.

Finally, it is important to consider that the trade-offs highlighted in this analysis are only a few of the many decisions countries must make when allocating their resources. Countries must also examine potential trade-offs with other investment areas, such as teacher training and school infrastructure, as well as trade-offs between different levels of education. All of these factors can influence countries' policy choices and the success of their educational systems (OECD, $2017_{[7] ;} ;$ OECD, 2018 $8_{[3]}$ ).

\section{The bottom line}

Decreasing class sizes, even by as little as one student, comes with a price tag. It is possible to "pay" for this increase by compensating with one of the other factors influencing the salary cost of teachers: lower teachers' salaries, less required instruction time for students or more teaching time for teachers. Across OECD countries there seems to be a trade-off between smaller class sizes and higher teachers' salaries, thus prompting the question of which policy leads to the best student outcomes. The evidence points to the importance of ensuring high-quality teaching above all else. Although higher salaries can help achieve that, several other factors will also influence the quality of the teaching force and of the country's educational system as whole. 


\section{FOR MORE INFORMATION:}

[2] Dynarski, S., J. Hyman and D. Schanzenbach (2013), "Experimental evidence on the effect of childhood investments on postsecondary attainment and degree completion", Journal of Policy Analysis and Management, Vol. 32/4, pp. 692-717, http://dx.doi.org/10.1002/pam.21715.

[5] Gromada, A. and C. Shewbridge (2016), "Student learning time: A literature review", OECD Education Working Papers, No. 127, OECD Publishing, Paris, https://dx.doi.org/10.1787/5jm409kqqkjh-en.

[1] OECD (2018), Education at a Glance 2018: OECD Indicators, OECD Publishing, Paris, https://dx.doi.org/10.1787/eag-2018-en.

[3] OECD (2018), Responsive School Systems: Connecting Facilities, Sectors and Programmes for Student Success, OECD Reviews of School Resources, OECD Publishing, Paris, https://dx.doi.org/10.1787/9789264306707-en.

[7] OECD (2017), The Funding of School Education: Connecting Resources and Learning, OECD Reviews of School Resources, OECD Publishing, Paris, https://dx.doi.org/10.1787/9789264276147-en.

[4] OECD (2016), PISA 2015 Results (Volume II): Policies and Practices for Successful Schools, PISA, OECD Publishing, Paris, http://dx.doi.org/10.1787/9789264267510-en.

[6] OECD (2016), "What influences spending on education?", Education Indicators in Focus, No. 46, OECD Publishing, Paris, https://dx.doi.org/10.1787/5jln041965kg-en.

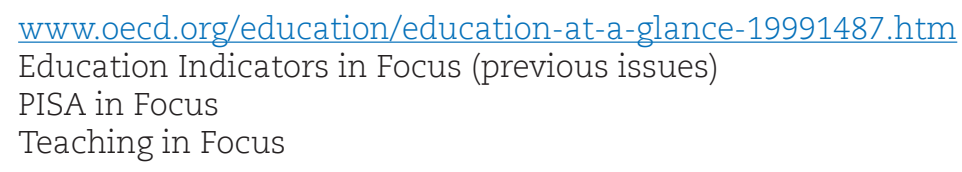

Photo credit: @ Christopher Futcher / iStock; @ Marc Romanelli / Gettyimages; @ michaeljung / Shutterstock; @ Pressmaster / Shutterstock This work is published under the responsibility of the Secretary-General of the OECD. The opinions expressed and arguments employed herein do not necessarily reflect the official views of OECD member countries.

This document, as well as any data and any map included herein, are without prejudice to the status of or sovereignty over any territory, to the delimitation of international frontiers and boundaries and to the name of any territory, city or area.

The statistical data for Israel are supplied by and are under the responsibility of the relevant Israeli authorities. The use of such data by the OECD is without prejudice to the status of the Golan Heights, East Jerusalem and Israeli settlements in the West Bank under the terms of international law. 